\title{
La biografía de Maximilian Nitze (1848-1906) y su contribución a la Urología
}

\author{
Verger-Kuhnke AB, Reuter MA, Beccaría ML. \\ Reuter Klink, Servicio de Urología del Hospital Karl-Olga, Hospital Escuela de la Universidad de Ulm. \\ Museo de Medicina Endoscópica, Max Nitze.
}

Actas Urol Esp. 2007;31(7):697-704

\section{RESUMEN}

LA BIOGRAFÍA DE MAXIMILIAN NITZE (1848-1906) Y SU CONTRIBUCIÓN A LA UROLOGÍA

Maximilian Carl Friedrich Nitze nació el 18 de septiembre de 1848 en Berlin, capital de Prusia. Siendo todavía estudiante en 1869 presenció en Heidelberg la primera nefrectomía efectuada por Gustav Simon (1824-1876), esto despertó en él, el interés por la Urología. En 1874 con 26 años se graduo en medicina doctorándose seguidamente.

El 2 de octubre de 1877, a los 28 años demostró en el instituto de Patología ante los miembros del Real Colegio Médico en Dresden el funcionamiento de su primer cistoscopio.

$\mathrm{El}$ indudable y valioso aporte de Nitze, fué hacer realidad la exploración endoscópica del sistema genitourinario e iniciar asi la era de los tratamientos quirúrgicos bajo visión directa,

La Urología adquirio la jerarquia de especialidad a principios del siglo XX, al independizarse de la cirugía, dermatología/venerologia, medicina interna y la anatomia patológica.

Palabras clave: Maximilian Nitze. Endoscopia. Uretro-cistoscopía. Urología moderna. Tratamiento quirúrgico.

\section{ABSTRACT}

THE BIOGRAPHY OF MAXIMILIAN NITZE (1848-1906) AND ITS CONTRIBUTION TO THE UROLOGY

Maximilian Carl Friedrich Nitze was born on the 18 of September of 1848 in Berlin the capital of Prussia. 1869 while still being a Student of the Heidelberg University the first nephrectomy of the world performed by Gustav Simon (1824-1876) woke his interest in urology. 1874 by the age of 26 he passed his state examination and obtained a doctor degree in medicine. On the 2 October of 1877 he presented the first cystoscope to the members of the Real Medical School in Dresden. Nitzes doubtless valuable contribution to urology was making real the endoscopical exploration of the genitourinary system and initializiring the era of surgical treatments under direct vision. By the beginning of the XX century urology reached the status of an independent specialty by separating from surgery, dermatology/venerology, internal medicine and pathology.

Keyword: Maximilian Nitze. Endoscopy. Urethro-cystoscopy. Modern urology. Surgical treatment.

$\mathrm{D}^{\prime}$ urante su vida entre los años 1848 y 1906 se desarrolló en Europa la Urología como una especialidad independiente de la cirugía y otras disciplinas.

Hombres como Desormeaux, (Paris 1853), introdujo el término endoscopia, la uretrotomía interna y modernizó el endoscopio de Bozzini, Midelldorpf (Breslau 1854), creó un ansa para resección y publico trabajos sobre el uso de la corriente galvánica en medicina, Ritter (Würzburg 1854) publicó sobre la detección de sangre, esperma y otros fluidos corporales en casos criminales, Fürstenheim (Berlín 1863) mejoró el instrumento de Desormeaux, Lotzbeck (Berlín 1858) primera descripción de la sutura vesical luego de la litotomía suprapúbica, Vogel (Berlín 1858) permitió la detección bioquímica de la glucosuria, Cruise (Dublin 1865), mejoras en sistema de iluminación del endoscopio, Lister (Londres1867), introdujo los principios de antisepsia y asepsia en medicina, Bruck (Breslau 1867), invento la diafanoscopia, Simon (Heidelberg 1869) efectuó la primera nefrectomía, Trouvé (Paris 1873), introdujo la fuente lumínica intracorporal, electoendoscopia y creación del poliscopio, Grünfeld (Viena 1874), creación del Punch para el tratamiento de la HPB sintomática, Bottini (Pavía 1874) utilización del electrocauterio a ciegas en el tratamiento de la HPB, Beneche (Berlín 1876), invento sistema de lentes para endoscopia, Leiter (Viena 1878) participo en la creación del cistoscopio, Lewandowski (Viena 1879), introdujo mejoras en la electroendoscopia, Schüler (Munich 1881), efectuó la primera orquidopexia con éxito, Fournier (Paris 1883), describió la gangrena que lleva su nombre, Newman (Glasgow 1883), utilizó la pri- 
mera lámpara eléctrica en un cistoscopio que no requería un sistema de enfriado, Dittel (Viena 1885), introdujo mejoras en el sistema de iluminación endoscópica, Trendelenburg (Berlín 1886) efectuó la primera pieloplastia, Brenner (Viena 1887), efectuó la primera ureteroscopia en la mujer, Antal (Budapest 1887) utilizó la cistoscopia neumática, sin el uso de líquidos, Fenwik (Londres 1888) construyó un cistoscopio más ergonómico y un cistoscopio infantil de $12 \mathrm{Ch}$, Boisseau de Rocher (Paris 1889) introdujo ópticas de gran ángulo, Pawlik (Viena 1889) realizo la primera cistectomía con derivación urinaria, Ultzmann (Viena 1890) introdujo innovaciones en el litotriptor, Güterbock (Berlín 1890) efectuó mejoras en los canales de irrigación e iluminación del cistoscopio, Tesla und Dàrsoval (Paris 1893) introdujeron la corriente de alta frecuencia y estudiaron su efecto en el cuerpo humano, Oberländer (Berlín 1893), mejoras del endoscopio, Guyon (Paris1893) sucesor de Jean Civiale y primer presidente de la Sociedad internacional de Urología, Casper (Berlín 1895) introdujo un segundo ocular para el aprendiz en un cistoscopio, Albarrán (Paris 1897), describió la anatomía de la próstata, efectuó la prostatectomía perineal y desarrolló la ureteroscopia, Rehfisch (Berlín 1897), introdujo y propago la urodinamia , Freudenberg, Wossidlo y Kollmann (Berlín 1900), introdujeron avances en la RTU, Lichtenberg (Berlín 1905-1906) desarrollo la cistografia y la pielografia retrógrada y Bloch (Berlín 1906) que publico un tratado sobre sexualidad como fenómeno sociocultural. Todos ellos , contribuyeron con sus ideas, innovaciones o descubrimientos al desarrollo de la Urología moderna.

La Sociedad de Urología francesa fundada en 1896 es la primera en su género, y es esta quien sirve de inspiración al resto de los paises europeos, que a comienzos del siglo XX fundan las distintas sociedades. Le sigue en 1906 la Sociedad alemana de Urología, en 1908 la Sociedad italiana de Urología y en 1911 la Sociedad española de Urología entre otras.

\section{BIOGRAFÍA}

Maximilian Carl Friedrich Nitze nació el 18 de Septiembre de 1848 en Berlín, capital de Prusia. En 1874 con 26 años se graduó en medicina y obtuvo el título de doctor seguidamente. Siendo todavía estudiante en 1869, presenció en Heidelberg la primera nefrectomía efectuada por Gustav Simon (1824-1876), esto despertó en él, el interés por la Urología ${ }^{1}$ (Fig. 1).

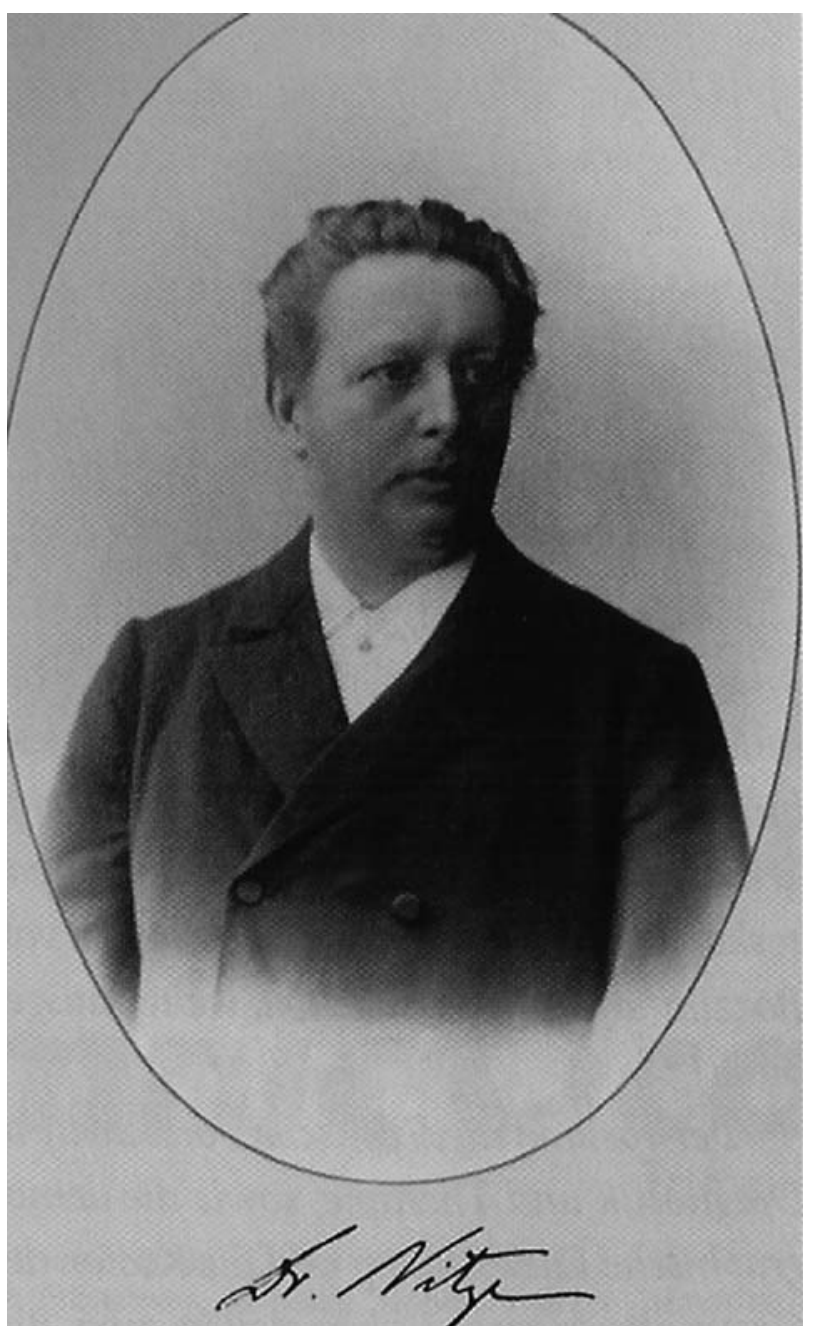

FIGURA 1. Maximiliam Nitze.

En 1875 ingresó como médico en el servicio de medicina interna del hospital estatal en Dresden. Al mismo tiempo trabajaba en el servicio de Ginecología, el Profesor Dr. Justus SchrammVogelsang utilizando la diafanoscopía como medio de diagnóstico complementario para las patologías de la pelvis femenina ${ }^{2}$.

Nitze participaba durante las exploraciones ginecológicas y fue así donde tuvo su primer contacto con el instrumento fabricado por Bruck, que utilizaba un alambre de platino incandescente como fuente lumínica, recubierto por un doble vidrio y con un sistema de enfriado por agua circulante $^{3}$. En esa época fue cuando a Nitze le abordaron los primeros pensamientos sobre la posibilidad de la exploración transuretral de la vejiga por medio de un instrumento.

Un suceso afortunado, como escribiría él mismo más tarde, llevó al joven médico más cerca de su 
objetivo. Un día, mientras limpiaba el objetivo cubierto de polvo de su microscopio, miró a través del mismo, para comprobar el resultado de la limpieza $\mathrm{y}$ al hacerlo pudo ver a través de la ventana, la imagen reducida e invertida de la iglesia que estaba al otro lado de la calle ${ }^{4}$.

En ese momento vió claro que sería posible fabricar un instrumento para explorar órganos o cavidades en forma de telescópio con un sistema de lentes y aumento que permitiera una imagen clara de las superficies observadas. Desde un principio pensó Nitze en explorar todas las cavidades expuestas al acceso de su instrumento, como había propuesto años antes en 1807 Bozzini en Frankfurt con su "conductor lumínico".

Poco tiempo despúes se decidió de forma consecuente a la fabricación de un instrumento para la visualización de la uretra y vejiga y sus posibles opciones terapéuticas con el mismo.

\section{La invención del cistoscópio}

Entre el 1 de julio de 1876 y el 30 de septiembre de 1878 trabajó Nitze en el Servicio de Cirugía a cargo del Dr. Leonhardi en Dresden y hasta noviembre de 1878 en el servicio de Obstetricia ${ }^{5,6}$. Fue en esa época que animado por el ginecólogo Schramm-Vogelsang, se propuso mejorar un instrumento para el exámen de los órganos y cavidades internas. Junto a un fabricante de instrumentos de presición llamado Heinrich Deicke de Dresden y un óptico del instituto de Física de la Universidad de Berlín llamado Louis Beneche, comenzaron con el trabajo.

Beneche habia construido ya una óptica con 3 lentes de aumento que permitian a una distancia de $6 \mathrm{~cm}$ de la superficie del órgano a explorar una imagen de $6 \mathrm{~cm}^{2}$. Para la iluminación de la cavidad orgánica a revisar se decidió Nitze por utilizar el alambre de platino incandesente enfriado por agua helada.

A mediados de 1876 poseía ya Nitze un modelo para la exploración transuretral de la vejiga, con un diámetro de 19-20 Charriere ${ }^{7}$.

Pero fué en el otoño de 1877 cuando el aparato estaba tan avanzado que ya podía utilizarse en pacientes ${ }^{8}$. Con su instrumento pudo identificar correctamente el "veru-montanum" en la uretra prostática. Su amigo y colega Felix Oberländer (1849-1915) siguió de cerca toda la fase inicial de la fabricación de este primer uretroscópio y lo utilizó con pacientes el mismo año de 1877.
El 2 de octubre de 1877, a los 28 años demostro junto a su asistente Alexander Schwede en el instituto de Patología ante los miembros del Real Colegio Médico de Sajonia en la ciudad de Dresden, el funcionamiento de su primer cistoscopio.

Entre los participantes se encontraba el patólogo Birch-Hirschfeld quien también tuvo la oportunidad de utilizar el aparato y poder reconocer, sin dificultad alguna, las piedras introducidas en la vejiga. Ese día fueron todos los presentes, sin saberlo, testigos del nacimiento de la endoscopía moderna.

En las semanas siguientes, emplearon el nuevo instrumento no sólo para la exploración y observación de la uretra y vejiga, sino también de la laringe, cavidad naso-faringea, esófago y estómago.

El instrumento poseía dos particularidades especiales:

1. La fuente de luz se encontraba en la punta misma del aparato.

2. La óptica, las lentes y prisma permitían el aumento de la superficie explorada.

Con este instrumento se sentaron las bases fundamentales de la endoscopia clínica moderna. Su utilización se efectuo tanto en el campo de las afecciones genitourinarias como gastroenterológicas. Los principios básicos de esta técnica diagnóstica y terapéutica se conservaron hasta la actualidad $^{9}$ (Fig. 2).

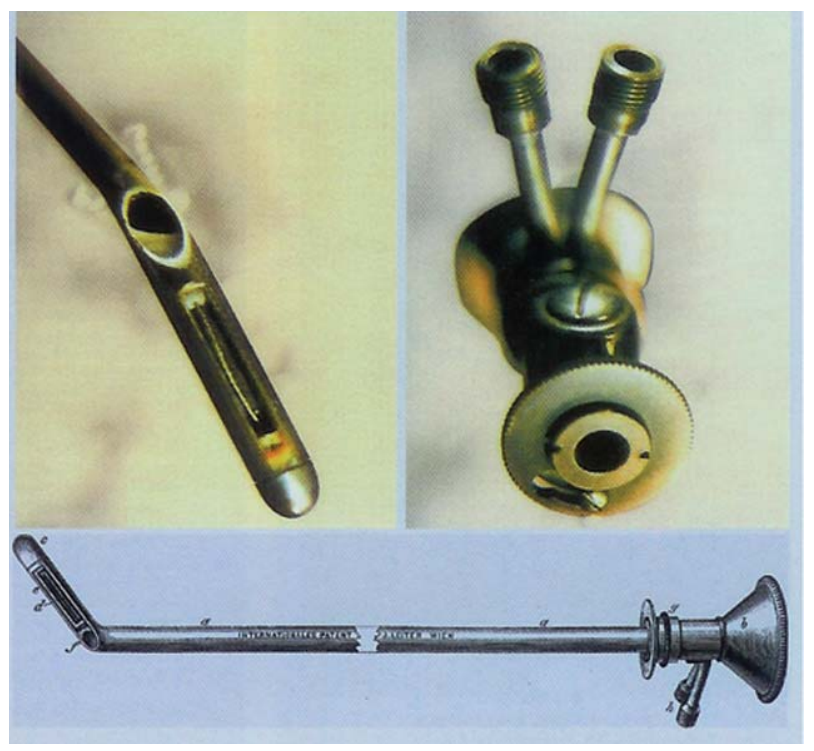

FIGURA 2. Primer cistoscopio de1877 (obsérvese el alambre de platino). 
Los autores antiguos que efectuaron algún tipo de cateterismo transuretral, describieron, sin darle la importancia debida en sus publicaciones, el uso de lubricantes tales como, aceite de oliva, queso blando o manteca para facilitar la maniobra, algunos incluso omitieron su utilización.

Max Nitze describe como lubricación uretral la utilización exclusiva de glicerina durante las cistoscopías, ya que todos los productos grasosos antes mencionados, producian distorciones en el campo visual al formar grumos y enturbiar las lentes (Fig. 3).

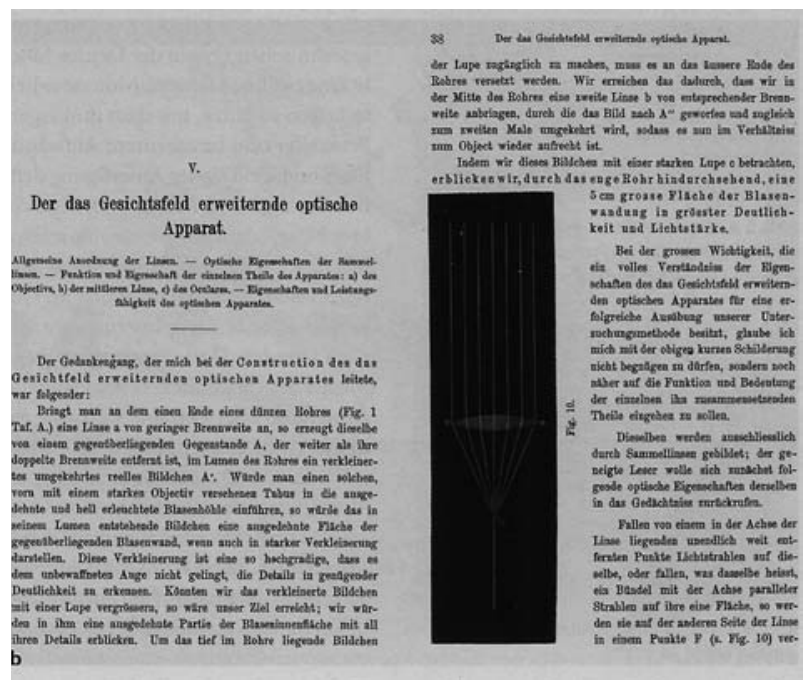

FIGURA 3. Publicación científica de Nitze sobre la óptica del cistoscopio.

Hacia 1893 Félix Guyon (1831-1920), uno de los más renombrados Urólogos de la escuela francesa, describe la fabricación de un producto para la instilación intrauretral en base acuosa con glicerina, jabón, carbol y jugos de diversas plantas con propiedades antisépticas.

Desde la introducción de la antisepsia en 1867 por Lord Joseph Lister (1827-1912) y la creación de la bacteriología moderna por Louis Pasteur (1822-1895) comienza a ser en la Urología de suma importancia, el cateterismo uretral aséptico o estéril para evitar infecciones. Algunos médicos empleaban en esa época para tal fin una solución intrauretral de ácido bórico al 3\%. La anestesia local de las mucosas con una solución de cocaína al 1-2 \% se introdujo en 1884, pero debido a que algunos pacientes fallecieron al aplicársele esta solución, Wossidlo recomendaba (1854-1918) el empleo de tutocaína o eucaína al $2 \%{ }^{10}$.

\section{Disfusión del cistoscópio}

Max Nitze se puso seguidamente en contacto con cuatro firmas distintas para la fabricación en serie de sus instrumentos. Deicke propuso a su amigo Josef Leiter de Viena, quien se puso en contacto con Nitze a traves del correo el dia 29 de junio de 1878. Ese mismo verano viajó Leiter a Dresden para ponerse al tanto de todos los detalles del nuevo aparato y poder así efectuar cambios con la intención de optimizar el funcionamiento del nuevo uretro-cistoscópio. Unos pocos meses después, en octubre de 1878 habían introducido ya varios cambios, pero Nitze no del todo satisfecho con el trabajo hecho, decidió trasladarse a Viena, para pasar una temporada en la ciudad y así poder mejorar aún más el manejo de su instrumento ${ }^{1,11}$. En 1879 le agregaron un prisma de cristal en la punta misma del instrumento para poder así ver en ángulo recto mejor el interior de la vejiga, el techo y los meatos ureterales. Esto aportaba una mejora considerable a la óptica de $0^{\circ}$, que se habÍa estado utilizando hasta entonces.

Después de 15 meses de trabajo en conjunto presentaron el 9 de mayo de 1879 el primer Nitze-Leiter uretro-recto-cistoscópio ${ }^{12}$.

Nitze mantiene un discurso ante la academia de médicos en Viena: "sobre el método de la iluminación de las cavidades del organismo humano“, que es recibido con gran aceptación por parte del público. La comunidad científica internacional, ve en el aporte técnico de Nitze y en la endoscopia un avance importante ${ }^{13}$.

El 9 de abril de 1880 habla en el $9^{\circ}$ Congreso alemán de Cirugía en Dresden y el día 10 de abril de 1880 hace una nueva demostración en el instituto de Patología.

El día 22 de abril de 1880 efectúa Nitze otra presentación de su invento en el hospital de la Charité en Berlin, quedando los presentes fuertemente impresionados, ya que nuevamente detectan las piedras y cuerpos extraños introducidos en la vejiga de un cadáver.

Ese mismo año inaugura Nitze con 32 años de edad un consultorio en Berlín, en la Wilhelmstraße 43, donde atiende enfermedades de vejiga y riñones. A su vez inaugura también un Policlínico urológico en Berlín. En ambas direcciones imparte regularmente cursos sobre su método diagnóstico, tanto para colegas nacionales como extranjeros. 
El sistema de enfriado del alambre incandesente, a través de agua, demostró ser un implemento caro y técnicamente dificil de utilizar, lo que hacía de la uretro-cistoscopia un método diagnóstico dificultoso. Nitze abandonó poco tiempo después las investigaciones sobre los instrumentos endoscópicos para el estómago, faringe, esófago y recto dedicandose exclusivamente al desarrollo de la endoscopia urológica.

En 1886 se produce otro avance de capital importancia en la endoscopía, éste sería la introducción de la lámpara miñon por Valentine, después de la invención de la lámpara eléctrica por Thomas Alva Edison en el año 1879.

Este avance implica el abandono del complicado sistema de enfriado que requería el alambre de platino incandecente, de esta manera logró simplificar el instrumento, haciendolo más maniobrable, además de abaratar significativamente los costos de la producción.

El 15 de abril de 1887, presenta Nitze, en el $16^{\circ}$ Congreso de Cirugía alemán en Berlín el nuevo cistoscopio con la lámpara eléctrica miñon ${ }^{6}$.

En otra disertación y hablando por primera vez, sobre el tratamiento endoscópico de los tumores vesicales, el día 20 de septiembre de 1887, Nitze, enuncia la posibilidad de resecar los pólipos vesicales utilizando su instrumento ${ }^{14,15}$.

En 1894 aparece el primer atlas con fotografias intravesicales obtenidas a través del cistoscopio. El ejemplar poseía 10 tablas con 60 figuras en color, así como también grabados fotográficos sobre distintas patologías. Este atlas se puede considerar el primer tratado de importancia sobre el tema.

Nitze fué desde 1886 el editor responsable de la revista sobre Urología "Centralblatt für die Krankheiten der Harn und Sexualorgane”.

En 1889 publica Nitze en Wiesbaden, Alemania, un libro sobre la cistoscopia, en el reconoce los méritos de Bozzini y del aporte que hizo a la Urología, al ser considerado precursor de la endoscopia ${ }^{16}$.

Debido a todos estos antecedentes, el $11 \mathrm{de}$ agosto de 1900, se le otorga a Max Nitze el título de Profesor extraordinario, que lo habilita para la enseñanza de la Urología ${ }^{17}$.

El año de la fundación de la Sociedad Americana de Urología (AUA) en 1902, se le nombra a Nitze, "miembro honorable" de dicha sociedad en la ciudad de New York ${ }^{16}$.
En 1904 se le otorga el premio "Grand Prix" durante el Congreso Internacional de Medicina celebrado en el Hospital Necker de Paris, debido a sus importantes aportes a la Medicina.

Al celebrarse en 1904 los 25 años de la primera cistoscopia efectuada en Viena el 9 de mayo de 1879, todos los Urólogos del mundo le rinden homenaje a través de un escrito, a los cuales contesta con agradecimiento.

El médico y cirujano Bernhard von Langenbeck elogió a Nitze con las siguientes palabras:

"El aporte que a través de la endoscopia de la vías urinarias, nos hace Nitze, demuestra la importancia del método, que nos permitirá en un futuro efectuar diagnósticos y tratamientos quirúrgicos de las vías urinarias con una gran precisión. Bajo estas condiciones se pronostica para la cirugía urológica un futuro favorable" (Figs. 4 y 5).

\section{El cistoscopio quirúrgico y la terapia endoscópica}

A principios del siglo XX, poseia Nitze la mayor cantidad de pacientes urológicos tratados por vía

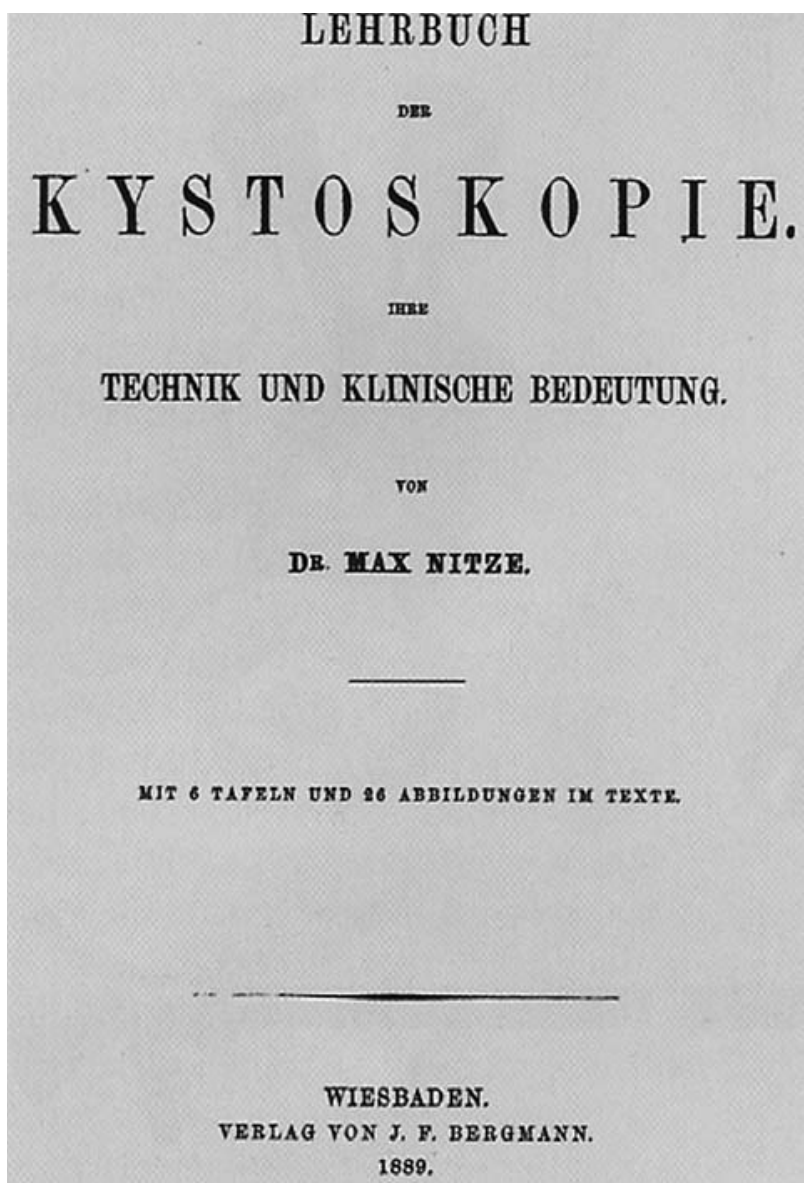

FIGURA 4. Primer libro sobre la cistoscopia de Max Nitze. 


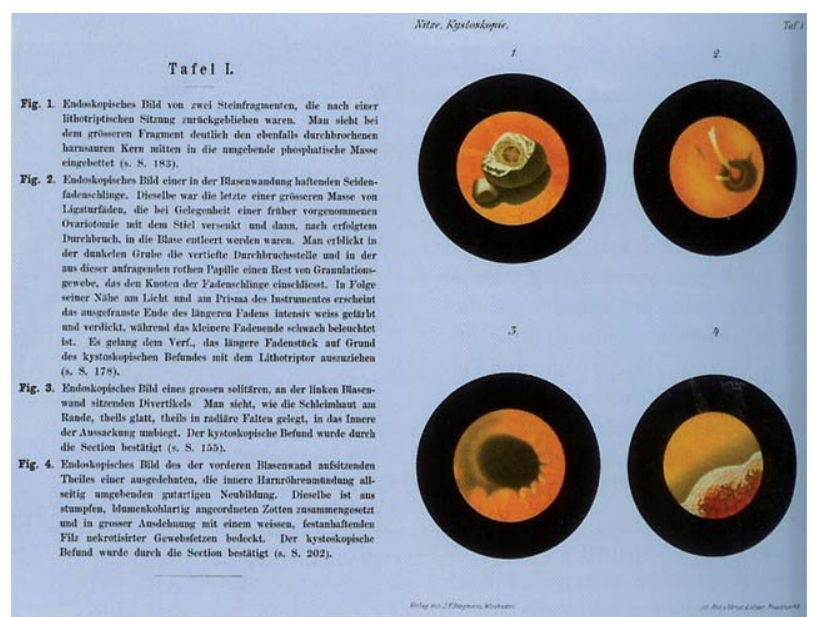

FIGURA 5. Imágenes endoscópicas del atlas de cistoscopia.

endoscópica. Todas las semanas, efectuaba varias operaciones vesicales y renales ${ }^{18}$.

Al diagnóstico endoscópico seguía ahora el tratamiento por la misma vía. En trabajo conjunto con los fabricantes de instrumentos medicinales Paul Hartwig, Hirschmann y a partir de 1896 Louis y Heinrich Löwenstein, construyó Nitze numerosos y distintos tipos de endoscópios.

Por ejemplo:

1. El cistoscopio con irrigación continua (1889)

2. El cisto-ureteroscopio para fotografiar (1893)

3. El cistoscopio para operaciones endoscópicas (1891-1894) (Fig. 6)

4. El ureteroscopio (1891-1894)

5. El cistoscopio para evacuar la vejiga (1897)

Introdujo con el nuevo cistoscopio para operaciones (precursor del resectoscopio), la cirugía endoscópica para el tratamiento de los tumores vesicales (Fig. 7).

Con el ansa de Middeldorpf (1854), se procedía bajo visión directa a "enlazar" el pólipo vesical, con la utilización de corriente eléctrica, gene-

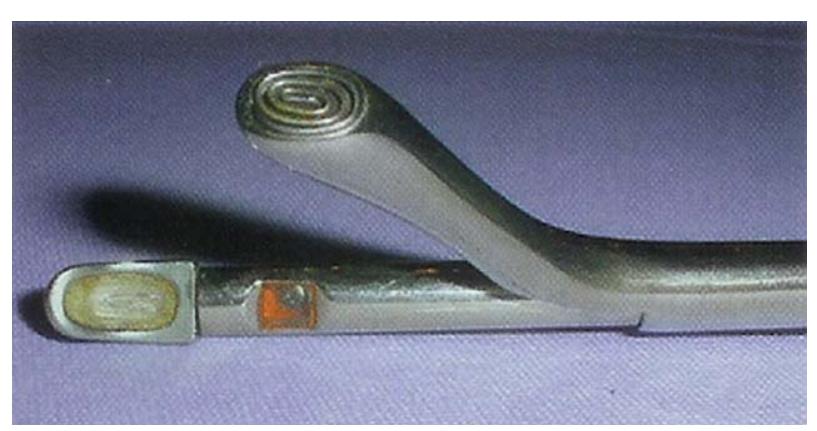

FIGURA 6. Cistoscopio para operaciones (1891-1894) con el ansa de Middeldorpf.

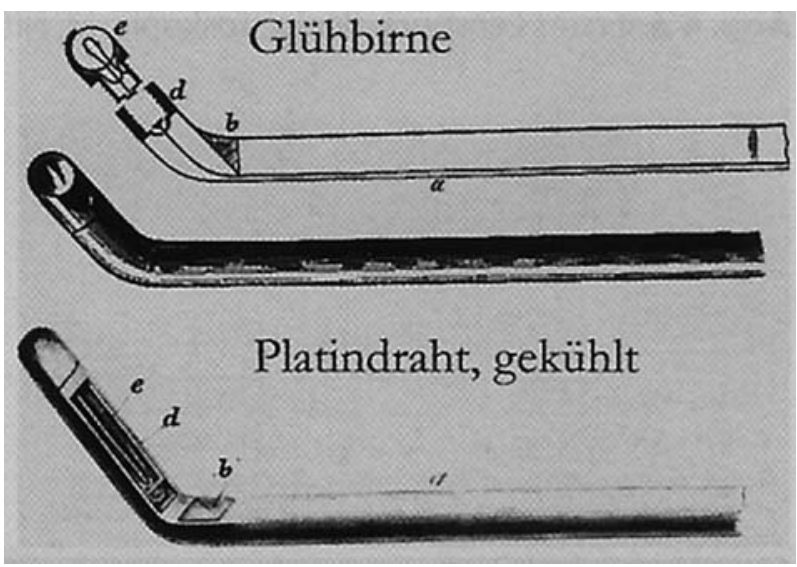

FIGURA 7. Cistoscopio con lámpara miñon (arriba) y con al alambre de platino (abajo).

rándose una incandesencia del alambre, que producía un corte del tumor y a su vez la coagulacion de la superficie.

Operó de esta forma 150 tumores vesicales, fracasando en 2 casos y produciendo la muerte de 1 paciente.

La litiasis vesical así como la extracción de cuerpos extraños fue perfeccionada por Nitze a través de diversos dispositivos en forma de pinza, pero bajo visión directa, a diferencia de sus predecesores que lo hacían a ciegas ${ }^{19}$.

Max Nitze inauguro también la exploración del uréter creando el catéter obturador del ureter, para así obtener muestras de orina del riñon contralateral. En 1895 introduce la ureteroscopía en el varón, siendo éste su último aporte a la endourologia ${ }^{20}$. En 1887 describía Brenner la ureteroscopia en la mujer. Nitze reconoce tiempo despúes, la superioridad de la uña de Albarrán para la exploración con catéteres del ureter, e incorpora dicho implemento a sus propios modelos.

En 1897 Nitze escribe sobre el tratamiento quirúrgico endoscópico de la hiperplasia benigna de próstata con la utilización del galvanocauterio $^{4}$.

Al final, él tampoco permite una necesaria modificación y modernización del sistema óptico ya que tiene numerosas desaveniencias con algunos colaboradores ${ }^{21}$. Fue tarea de Ringleb después de la muerte del maestro introducir modificaciones y mejoras en este sentido, ya H.H. Young en 1904 en New York habia sugerido mejoras en el sistema óptico.

El 21 de febrero de 1906 a los 57 años de edad sufre Max Nitze un ataque apopléjico, falleciendo un día después en su domicilio de Berlín. Su 
cuerpo fue enviado a su querida madre en Eisenach donde fue sepultado en el cementerio local (Fig. 8).

Después de su muerte, se comienza con la edicion de la Revista de Urología y se funda en Stuttgart en 1906 la Sociedad alemana de Urologia (Deutsche Gesellschaft für Urologie). Pero ya hacia 1896 había insinuado Nitze la nesecidad de organizar una sociedad de Urólogos.

\section{DISCUSIÓN}

La utilización del catéter transuretral, la circuncisión, la punción del hidrocele y la litotomía vesical suprapúbica o perineal son algunos de los procedimientos médicos más antiguos y a su vez la base de la Urología.

La escuela hipocrática y el mismo Claudio Galeno (129-199), se servian de la observación de numerosos signos o síntomas en los pacientes para efectuar el diagnóstico y uno de ellos era la observación de orina (color, consistencia, sedimento, cantidad, partículas suspendidas, etc.). La mátula, recipiente de vidrio destinado a la observación de orina, pasó a ser un símbolo de la profesión médica.

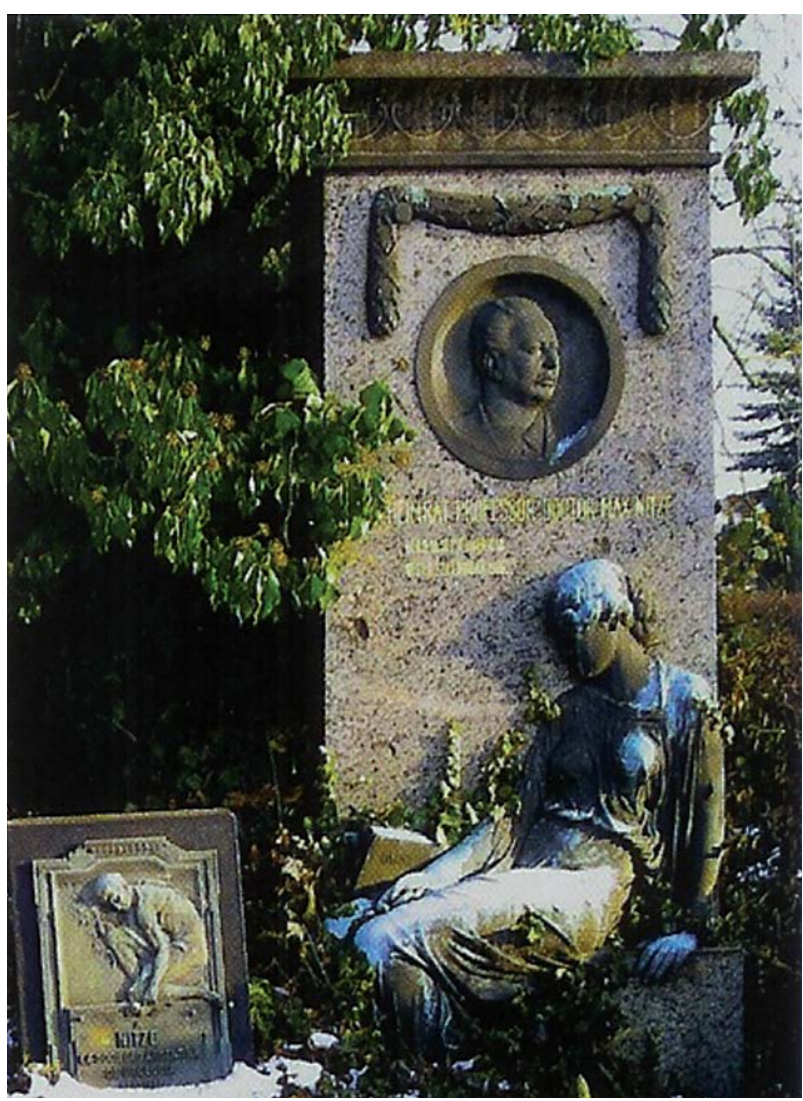

FIGURA 8. Tumba de Max Nitze.
Paracelo (1493-1541) rechazó el principio de la medicina antigua que hacía responsable a la "discrasia" o sea la mezcla inapropiada de los fluidos corporales como origen de todas las enfermedades, fue él precisamente quien divulgó el analisis de la orina a través de la destilación, con la intención de diagnosticar enfermedades que se mantenian ocultas a la observación visual.

Pero fue Jöns Jakob Berzelius (1779-1848) quien introduce el análisis químico de la orina y hacia 1828 describe la presencia de urea, que se transformaría en una de las sustancias más importantes para el diagnóstico de las enfermedades renales.

El término UROLOGÍA significa "el que observa la orina" aparece por primera vez en un texto en 1738 en una publicación de J. Junker en Halle, y deriva del vocablo UROSCOPIA.

La idea de extraer cálculos vesicales de forma menos agresiva que la litotomía abierta, ya sea perineal o suprapúbica, se remonta a la antigüedad, pero fue Franz von Paula Gruithuisen (1774-1852) quien en 1813 en Munich, sienta las bases para un tratamiento traunsuretral a ciegas $^{23}$. El trabajo de éste sirve de inspiración a Jean Civiale (1792-1867) quien fabrica un litotriptor transuretral que consta de 42 piezas. Al final de su carrera laboral había tratado 1.400 pacientes entre hombres, mujeres y niños y logrado reducir a un 5\% la letalidad del procedimiento (en contraste con la litotomía abierta que llegaba al 50\%). La duración de la operación era de 5 a 15 minutos y podía repetirse, de ser necesario a los 3 ó 4 días.

En la $2^{\circ}$ mitad del siglo XIX y comienzos del $\mathrm{XX}$ se produjeron numerosos y notables aportes a la medicina.

W. Morton (1819-1868) y S. Wells (1815-1848) introducen la anestésia general, lo que permitió ampliar las indicaciones quirúrgicas.

El principio de antisépsis y asépsis dictado por Lord Lister (1827-1912) a partir de 1868 adquieren rápida difusión con la consiguiente reducción de la morbi-mortalidad post-operatoria.

La creación de instrumentos quirúrgicos que permiten un adecuado control de la hemorragia intraoperatoria como la pinza de Jules Pean (1830-1898), así como la producción de catéteres vesicales de goma blanda por Nelaton, posibilitaron una técnica operatoria más sutil y menos traumática y una mejor asistencia del paciente después de la operación. A estos adelantos se les 
sumará unos años despúes los antibióticos, que permitirán aún más, mejorar los resultados obtenidos.

Dos hechos de importancia en la historia de la medicina contribuyeron a la creación de la Urología moderna como una especialidad independiente.

En 1869 fúe operada la paciente de 46 años Margareta Kleeb (1820-1878) quien presentaba una fístula uretero-vaginal complicada del lado izquierdo después de ser sometida a una histeroovariectomía. El tratamiento conservador había fracasado y la lavandera había perdido el trabajo que la sustentaba; la paciente recibió la primera nefrectomía por vía de lumbotomía, realizada por el Profesor Gustav Simon en Heidelberg, quien había efectuado con anterioridad experimentos en animales para comprobar la viabilidad de la operación.

El segundo gran aporte a la Urología lo hace en 1877 Max Nitze con la invención del cistoscopio, que pasará a ser el instrumento insignia de la especialidad.

\section{CONCLUSIÓN}

Llevar a la práctica y hacer realidad la exploración endoscópica del sistema genitourinario e iniciar así la era de los tratamientos quirúrgicos bajo visión directa, son los indudables y valiosos aportes realizados por Nitze a la Urología.

Sus experiencias fueron recopiladas en el atlas de las cisto-fotografias y en un libro sobre la utilización práctica de la cirugía por Bergmann y Bruns.

La cistoscopia y la utilización del trócar suprapúbico fueron el origen que permitió el desarrollo de numerosas ramas dentro y fuera de la Urología, como la laparoscopía (antes denominada celioscopía por Kellings en 1901), la toracoscopia (Jakobeus 1913), la artroscopia (Tagaki, Bircher 1921), la resección transuretral con trócar (RTU-P de baja presión hidraúlica), la retroperitoneoscopia (Wittmoser 1973) asi como la nefroscopia percutánea ${ }^{2}$.

Todo esto nos permite afirmar que sin duda alguna, Max Nitze fue un pionero de la Urología moderna y de los tratamientos quirúrgicos endoscópicos lo que permitio crear una especialidad independiente como la conocemos hoy en día.

\section{REFERENCIAS}

1. Reuter MA. Maximilian Nitze (1848-1906): der Durchbruch in der medizinischen Endoskopie. Wegbereiter der Urologie. Springer, Berlin, Heidelberg, New York, 2002.
2. Reuter MA. Maximilian Nitze (1848-1906) Geburtshelfer der Urologie. Museum für Medizinische Endoskopie Max Nitze, Klinik für Urologie am KOK, Stuttgart, Germany. Der Urologe 2006;45: 1076-1083.

3. Zamann AP, Zajaczkowski T, Praxis Müllheim an der Ruhr, Klinik für Urologie, Kath. Kliniken Essen-Nord, Marien HospitalGermany. Julius Bruck (1840-1902) Sein Beitrag zur Weiterentwicklung der Endoskopie. Der Urologe B 2002;42:45-39.

4. Nitze M. Über die Galvanokaustik der Prostatahypertrophie. Zentralblatt Harn Sexualorgane 1897.

5. Keller J. Die Erfindung des Cystoskpops. Deutscher Gesundheitswesen 9:1-8.1949

6. Keller J. Die Erfindung des Blasenspiegels. Ges.für Urol 1953. Z Urol Sonderheft. 1949;1954:24-52.

7. Oberländer FM. Die Nitze-Leiterschen urethro-und cystoskopischen Instrumente und ihre Anwendungsweise. Ber Klein Wochenschr. 1879;48:709-713.

8. Nitze M. Über eine neue Beleuchtungsmethode der Höhlen des menschlichen Körpers. Wien Med Presse 26:851-858, 1979.

9. Reuter MA. Geschichte der Endoskopie. Krämer Stuttgart 1998.

10. Moll F, Rathert. Zur entwicklung des Kathetergleitgels. Urologische Klinik der Stadt Köln. Der Urologe B 2001 41:272275.

11. Reuter MA. Entwicklung der Endorologie. Illustrierte Geschichte der Urologie. Springer, Berlín, Heidelberg, New York, 2004.

12. Leiter J. Elektroendoskopische Instrumente. Wien 1880. Max Nitze Museum 1985.

13. Dittel v. L. Demostration des Cystoskops in Wien (Herbst 1879). Wien Med. Wochens. 22:794. 1886

14. Ringleb O. Zur Erinnerung an Max Nitze. Z Urol Chir 36:1-15, 1939.

15. Ringleb O. Maximilian Nitze und die Erfindung des Cystoskops. Z Urol 1939;33:579-590.

16. Reuter HJ, Reuter MA. Bozzini und die Endoskopie des 19.Jahrhunderts.Krämer, Stuttgart, 1988.

17. Nitze M. Lehrbuch der Kystoskopie. Bergmann, Wiesbaden, 1889.

18. Rothschild A. Max Nitze und die Urologie. Z Urol. 1928;22:743750 .

19. Nitze M. Die intravesikale Operation der Blasengeschwülste. Zentralblatt Harn Sexualorgane 7:377-405, 1896.

20. Nitze M. Beiträge zur Endoskopie der männlichen Harnblase. Arch Klein Chir. 1887;36(3),

21. Casper L. Autobiographie. Hartcout, Brace and Co. New York, p 88. 1940.

22. Zamann AM(1), Zajaczkowski T(2), Rathert P(3)

(1) Praxis Bochum,

(2) Klinik für Urologie, Kath. Kliniken Essen-Nord. Marien Hospital-Germany.

(3) Klinik für Urologie und Kinderurologie, Düre, Germany. Professor Franz von Paula Gruithuisen, Mediziner und Astronom (1774-1852) Der Urologe B 1999;39:539-545.

Correspondencia autor: Dr. A. Verger Kuhnke

Hospital de Torrevieja

CV-95 Partida la Ceñuela - 03186 Torrevieja (Alicante)

Tel.: 966928861

E-mail autor: abverger@torrevieja-salud.com

Información del artículo: Original - Historia de la Urología

Trabajo recibido: diciembre 2006

Trabajo aceptado: enero 2007 